\title{
Temperature Dependence of the Pre-breakdown and Breakdown Phenomena in Natural Esters under AC Stress
}

\author{
B. Sékongo ${ }^{1,2}$, U. Mohan Rao ${ }^{2 *}$, I. Fofana ${ }^{2,3}$, M. Jabbari ${ }^{3}$, S. Akre ${ }^{2,4}$ and Z. Yeo ${ }^{4}$ \\ ${ }^{1}$ Ufr-SSMT Laboratory of Physics Condensed Matter and Technology -Université Félix Houphouët Boigny de \\ Cocody-Abidjan Côte d'Ivoire. \\ ${ }^{2}$ Research Chair on the Aging of Power Network Infrastructure (ViAHT), Department of Applied Sciences, \\ University of Quebec at Chicoutimi, Quebec, G7H 2B1, Canada. \\ ${ }^{3}$ International Research Center on Atmospheric Icing and Power Network Engineering (CenGivre), Department \\ of Applied Sciences, University of Quebec at Chicoutimi, Quebec, G7H 2B1, Canada. \\ ${ }^{4}$ Department of Electrical Engineering, Institute National Polytechnique, Yamoussoukro, Po Box 1093, Côte \\ d'Ivoire \\ "ohan.ungarala1@uqac.ca
}

\begin{abstract}
Natural ester dielectric fluids are being used as alternatives for mineral insulating oils in oil-filled power apparatuses. Although, partial discharges (PDs) are recognized as one of the main causes of degradation of dielectrics used in power equipment, their characteristic voltages appear to be temperature dependent. In this contribution, the pre-breakdown and breakdown behaviour of two natural ester fluids, extracted from canola oil (NE1) and soybean oil (NE2) is reported. To assess the effectiveness of the temperature dependence, $-5^{\circ} \mathrm{C}, 0^{\circ} \mathrm{C}$, and $+20^{\circ} \mathrm{C}$ have been identified as test temperatures. It was found that the different pre-breakdown and breakdown characteristic voltages increase with increasing temperature for both types of esters. The delay time is always longer for canola oil when compared to soybean oil regardless the test temperature. The analysis of the average propagation velocity of NE1 and NE2 indicates that PDs propagate faster in NE2 than in NE1. The field strength at the tip of the needle electrode during the inception of the streamers leading to breakdown, indicates that streamers in both oils are propagating in the slow mode. It is found that, temperature has a significant influence on the PDs' parameters for both fluids.
\end{abstract}

\section{Introduction}

Alternative dielectric fluids and condition monitoring studies for power and distribution transformers are subjects of interest for maintenance engineers and utilities [1-3]. The interest towards these dielectric fluids is due to various reasons including thermal and dielectric performances, the need for higher biodegradability and non-toxicity. These biodegradable oils (synthetic and natural esters) also support the lifetime extension of the transformer insulation system and depict a good compatibility with the solid insulation system $[1,2]$. However, the application of natural esters is limited to sealed transformers. This is because, natural esters undergo rapid oxidation when in contact with the surrounding air (for non-sealed transformers). Also, the viscosity, cost, and availability of diagnostic tools are limiting factors for natural esters filled equipment's maintenance. This is mainly because their properties cannot be directly correlated with those of a mineral oil, because their chemical compositions are very different. The interest and the growing demand for biodegradable fluids, stimulate research activities in this field. With increased industrial and research experiences, several utilities across the globe started using natural esters while some are testing their performance to meet the desired local requirements.

Various authors reported benefits of using the natural esters, compatibility of natural esters, service experience, and workability of natural esters. The details of which are summarized in [1,2]. The critical analysis of the latest literature available on pre-breakdown phenomena of ester fluids vis-à-vis mineral oils have been summarized in [3]
Also, the effect of temperature on the dielectric behaviour of ester fluids have been reported in [4].

It is to be mentioned that, natural ester exhibits a poor resistance to the lightning impulse streamers and has a poor viscosity profile at low temperatures as compared to mineral oils [4]. Therefore, the subject 'pre-breakdown and breakdown behaviour of natural esters' is having a great engineering importance. Evidence of streamers inception and breakdown events are detrimental to power transformers insulation design. Indeed, understanding the pre-breakdown events and breakdown phenomena is more important to improve the design aspects and dielectric safety margins of transformers. The properties of streamers and the breakdown behaviour of vegetable oils were compared to mineral oils and it was found that the streamers' inception mechanism is same in both liquids, whereas streamer propagation is faster in vegetable oils [5]. Several researchers investigated the feasibility and suitability of additives for improving the lightning impulse streamers' behaviour of natural esters $[6$, 7]. Most of investigations reported onto the pre-breakdown phenomena of natural esters was performed at room temperature. A review on this topic was recently summarized by authors of the same research group in [1] and "IEEE DEIS technical committee on Liquid Dielectrics" in [3].

The temperature dependence of the ester fluids and associated breakdown behaviour has been least emphasized in the literature. The effect of temperature on the prebreakdown phenomena of ester fluids have been investigated by few researchers [8]. However, only high temperature effects have been emphasized. There is a need in 
understanding PDs behaviour of these fluids from room temperature to temperature close to the pourpoint ones.

In this work, canola and soybean based natural ester fluids were subjected to high $\mathrm{AC}$ stress at $-5^{\circ} \mathrm{C}, 0^{\circ} \mathrm{C}$, and $20^{\circ} \mathrm{C}$. However, in extreme cold climatic regions, the fluidity of natural esters is hampered thus leading to other significant consequences $[1,3]$; the discussion of which is beyond the scope of this work. The aim of the present work is to improve the fundamental knowledge on the pre-breakdown and breakdown behaviour of canola and soybean oils as a function of temperature and viscosity under AC stress. While studying the delay time, PD pre-inception voltage (PDPIV), PD inception voltage (PDIV), breakdown streamer inception voltage (BSIV), breakdown voltage, and inception electric field stress at the tip of the needle electrode, streamer velocity, and viscosity at different temperatures. The behaviour of streamer growth and governing parameters were reported as a function of temperature under AC stress. An important parameter that has been introduced is the delay time $\Delta t$. The delay time $\Delta t$ is defined as the difference between the streamers pre-inception time (PDPIT) and the streamer leading to breakdown time (BSIT). The results of this study allow understanding the potential feasibility of vegetable oils for use in transformers serving in cold climatic regions.

\section{Effect of Temperature on Streamers Propagation}

In [9], it is reported that, the electric charge flow, which is associated with the pre-breakdown events, is temperature dependent. Also, it is well-established fact that moisture has an effect on the dielectric behaviour of any transformer insulation [10]. It is to be recalled that moisture distribution between the solid and liquid insulation significantly depends on temperature [11]. For temperatures between $0^{\circ} \mathrm{C}$ and the pourpoint (for example $-42^{\circ} \mathrm{C}$ for $\mathrm{MO}$ (Shell Diala), $-54^{\circ} \mathrm{C}$ for NE (Envirotemp 200) and $-56^{\circ} \mathrm{C}$ for SE (Midel 7131)), the dielectric performance of the oils worsens [12]. The oil is more viscous, its circulation slowed down, and become more susceptible to free moisture release. Consequently, the streamers' inception voltage decreases. For temperatures between $0^{\circ} \mathrm{C}$ and the fire point (e.g. $191^{\circ} \mathrm{C}$ for mineral oil Shell Diala, $265^{\circ} \mathrm{C}$ for natural ester Envirotemp 200 and $260^{\circ} \mathrm{C}$ for synthetic ester Midel 7131), the interplay between temperatures and viscosity influence the streamers propagation velocity [12]. For example, the propagation velocity of streamers in n-hexane increased from 2.3 to $2.7 \mathrm{~km} / \mathrm{s}$ for a temperature variation of 5 to $42^{\circ} \mathrm{C}$ at $25 \mathrm{kV}$ [13]. It is to be understood that, oil temperature plays a significant role on the hydrostatic pressure and the formation of weak pressure points. The hydrostatic pressure influences the characteristics of the streamers such as: stopping length, inception voltage [14]. Although the electric field is the main factor influencing streamer propagation [15], the reduction in hydrostatic pressure shows that streamer propagation is in the gas phase [16].

\section{Experimental and Samples}

\subsection{Experimental setup}

The experimental investigations were performed under AC stress using a point-plane electrode configuration. The laboratory setup used for the measurements is presented in Fig. 1. A $100 \mathrm{kV}, 5 \mathrm{kVA}$ high voltage transformer was used. The AC stress is applied through the resistor R, to the highvoltage needle electrodes. The capacitive divider allows having the waveform and the numerical values associated with the applied voltage during the measurement. An appropriate test cell has been designed to accommodate the point-plane electrode configuration with $180 \mathrm{ml}$ of insulating oil. The gap between the point-plane electrode arrangement was adjusted to $10 \mathrm{~mm}$. It is to be mentioned that all the measurements have been performed on this gap length. The radius of curvature at the tip of the point electrode (needle) made up of tungsten is $27.335 \mu \mathrm{m}$ while the ground electrode in stainless steel has a diameter of $120 \pm 1 \mathrm{~mm}$. The use of the needle electrode allows creating an intense electric field at the tip of the needle (because of the sharp edge). The discharge usually initiates at the tip of the point electrode. The light emitted by the ionization phenomena during the prebreakdown and breakdown process was collected by a "Hamamatsu Photonics R928P" photomultiplier tube (PMT). The PMT instantly detects any light emission at a wavelength ranging from 185 to $900 \mathrm{~nm}$ (from ultraviolet to infrared), with maximum efficiency at a wavelength of $400 \mathrm{~nm}$. It is to be mentioned that the PMT was fixed on the glass window of the climatic chamber. The role of the resistance $\left(R_{0}\right)$ connected in series with the test cell was to limit the leakage current. According to [8] the value of shunt resistance $R_{0}$ was set to $100 \Omega$. The voltage drop across this resistor was recorded continuously and used to compute the leakage current. The acquisition box allows the PC recording the different signals: applied voltage, PMT, drop voltage across a series resistor and current transformer signal (leakage current) through the DAQ.

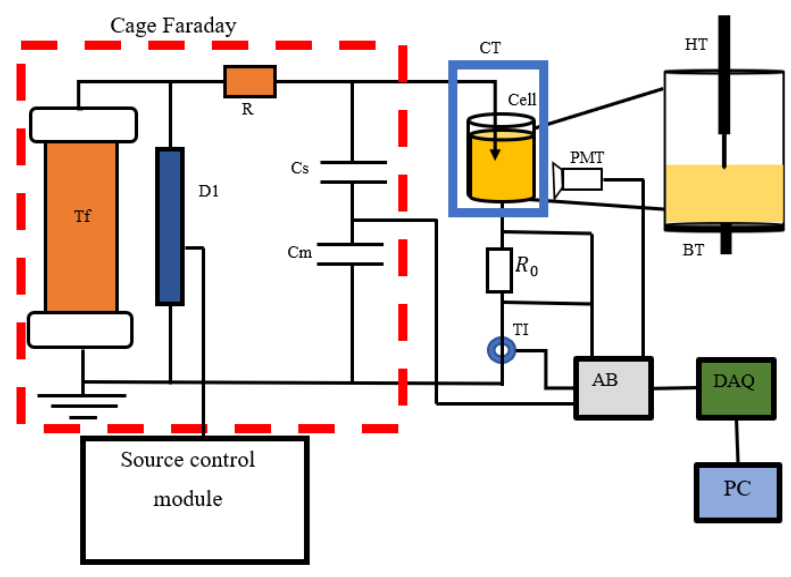

$a$

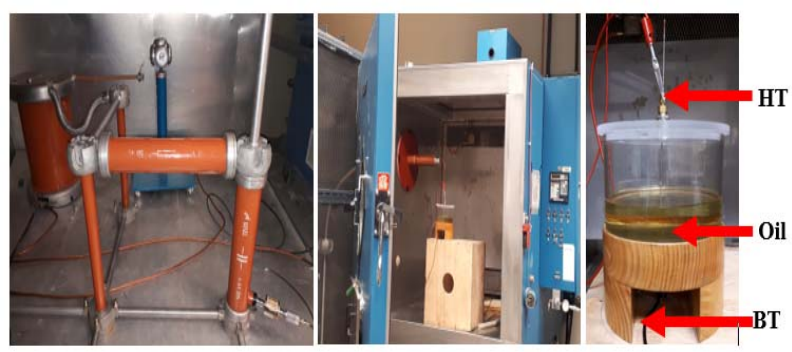


$b$

Fig. 1. View of the experimental setup.

(a)Schematic (b) HV source-climatic chamber and test cell

Tf: High voltage transformer;

D1: Capacitive divider 1 to record the applied voltage;

$\mathrm{R}$ : Current limiting resistor;

$\mathrm{Cs}$ and $\mathrm{Cm}$ capacitive divider 2;

Cell: test cell (HT: high voltage electrode and BT: low voltage electrode);

CT: Climatic chamber;

PMT: Photomultiplier Tube;

HT: High voltage electrode;

BT: ground electrode;

$R_{0}$ : Leakage current limiting resistance;

TI : Current transformer ;

$\mathrm{AB}:$ Acquisition Box ;

PC; Computer;

DAQ: Data Acquisition system.

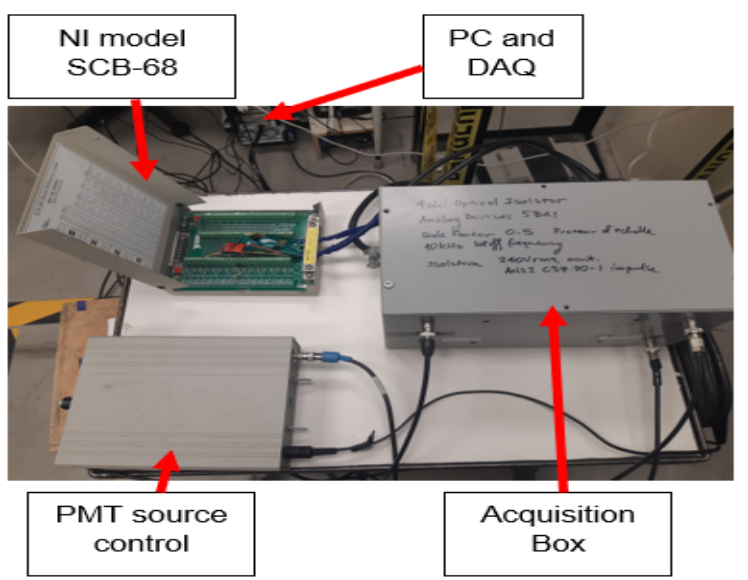

Fig. 2. Acquisition system

The acquisition box was connected to the adaptor of the National Instrument (NI) model SCB-68 Quick Reference Label series MOI-16 E which is connected to a DAQ (PCI$6251)$ in a computer. The acquisition system is shown in Fig. 2.

\subsection{Test temperatures selection}

In this work, the pre-breakdown behaviour of two different vegetable oils has been investigated at $-5^{\circ} \mathrm{C}, 0^{\circ} \mathrm{C}$, and $+20^{\circ} \mathrm{C}$ (ambient temperature). These temperatures are adopted to understand the temperature dependence of NE1 and NE2 while considering the pourpoint of the fluids. The pourpoint of NE1 and NE2 is $-30^{\circ} \mathrm{C}$ and $-10^{\circ} \mathrm{C}$ respectively. Therefore, the present testing temperatures are between $-5^{\circ} \mathrm{C}$ and room temperature $\left(+20^{\circ} \mathrm{C}\right)$. This will allow to understand the behaviour of the selected oils at low temperatures [1]. Such a behaviour will be interesting for the transformers in cold regions. Also, this transit temperature range is critical for the insulating oils when viscosity is considered. This is because for temperatures less than the $0^{\circ} \mathrm{C}$, viscosity of alternative fluids increases gradually [17].

\subsection{Insulating oils samples preparation and measurement procedures}

For the present study, fresh canola oil (NE1) and soybean oil (NE2) based natural esters are used. However, both the oils have been subjected to degassing and drying procedures for 48 hours under vacuum before starting the experiments. This was performed to avoid any moisture that is absorbed during handling and sampling of the dielectric fluids in the laboratory. 15 bottles of $180 \mathrm{ml}$ of each type of oil was used. For example, for NE1, 5 bottles of $180 \mathrm{ml}$ were used, for each temperature $\left(-5^{\circ} \mathrm{C}, 0^{\circ} \mathrm{C}\right.$ and $\left.+20^{\circ} \mathrm{C}\right)$. Each sample of $180 \mathrm{ml}$ was used for one test. The same procedure applied for NE2. Insulating oils were poured in the test cell and tested at different temperatures $\left(-5^{\circ} \mathrm{C}, 0^{\circ} \mathrm{C}\right.$, and $\left.20^{\circ} \mathrm{C}\right)$. The thermocouple is used to monitor the temperature of the oils while a programmable climatic chamber is used to set the desired measuring temperature. The AC voltage across the gap is raised at $1 \mathrm{kV} / \mathrm{s}$ up to breakdown. For a given temperature, five samples of each oil were tested. The result is the average of the five measurements. The same process is repeated at the desired test temperatures. The data are collected, and the results are analyzed in the MATLAB environment to derive different characteristics of streamers.

Also, the kinematic viscosity of the fluids was measured at the desirable test temperature using a rotational viscometer. For each temperature, five measurements are performed, and the average value is considered for the analyses. For the upcoming figures (except Figures 4 and 5), each dot (in a figure) is the average of 5 measurements. The viscosity measurement is shown in Fig. 3. The main properties of the NE1 and NE2 are presented in Table 1.

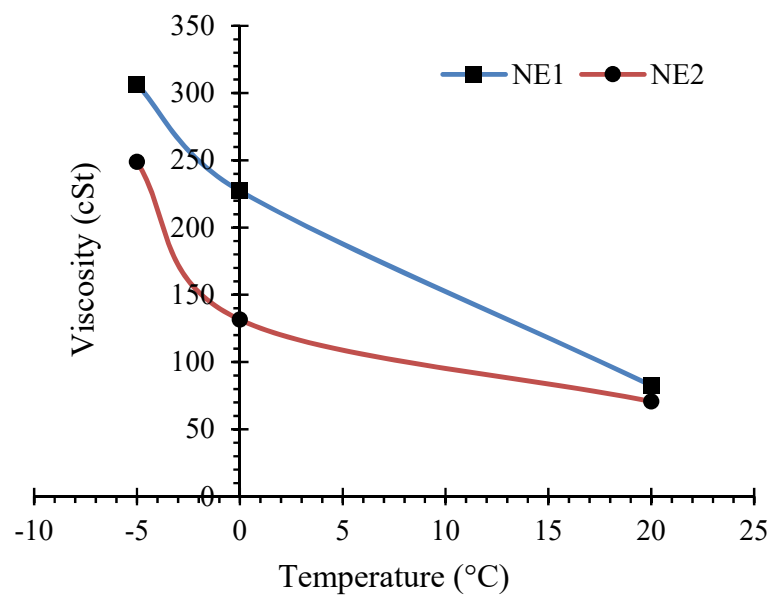

Fig. 3. Viscosity of the oils as a function of temperature.

Table 1 Properties of the liquids tested (NE1 and NE2)

\begin{tabular}{lccc}
\hline \multicolumn{1}{c}{ Properties } & Standard & NE1 & NE2 \\
\hline $\begin{array}{l}\text { Viscosity at } 40^{\circ} \mathrm{C}, \\
\mathrm{mm} 2 / \mathrm{s}\end{array}$ & ISO 3104 & 37 & 32 \\
\hline $\mathrm{AC} \mathrm{BDV}(\mathrm{kV})$ & IEC 60156 & $>75$ & $>75$ \\
\hline $\begin{array}{l}\text { Dissipation factor at } \\
90^{\circ} \mathrm{C} \text { and } 50 \mathrm{~Hz}\end{array}$ & IEC 60247 & $<0.03$ & $<0.03$ \\
\hline Permittivity at $20^{\circ} \mathrm{C}$ & IEC 60247 & 3.44 & 3.1 \\
\hline $\begin{array}{l}\text { Density at } 20^{\circ} \mathrm{C}, \\
\text { kg/dm3 }\end{array}$ & ISO 3675 & 0.92 & 0.92 \\
\hline Pour point $\left({ }^{\circ} \mathrm{C}\right)$ & ISO 3016 & -30 & -10 \\
\hline Flash Point $\left({ }^{\circ} \mathrm{C}\right)$ & ASTM D92 & $>315$ & $>315$
\end{tabular}




\begin{tabular}{llcc} 
Fire Point $\left({ }^{\circ} \mathrm{C}\right)$ & ASTM D92 & $>350$ & $>350$ \\
\hline $\begin{array}{l}\text { Moisture Saturation } \\
(\mathrm{ppm}) \text { limit at } 20^{\circ} \mathrm{C}\end{array}$ & ASTM1533 & 1100 & 1100 \\
\hline
\end{tabular}

The viscosity increases with temperature decrease as expected. However, the rate of viscosity decrease of NE1 is higher than that of NE2 at $-5^{\circ} \mathrm{C}$ and $0^{\circ} \mathrm{C}$. At $20^{\circ} \mathrm{C}$, both oils seem to have the same viscosity.

\subsection{Measurements at $0^{\circ} \mathrm{C}$ for $N E 1$}

The voltage was increased at $1 \mathrm{kV} / \mathrm{s}$ from $0,5 \mp$ $0,2 \mathrm{kV}$ up to breakdown of the oil. The acquisition system simultaneously records four signals: the applied voltage, the voltage drop across the resistance $R_{0}$, the leakage current using the TI and the PMT signal. The PMT helps determining the initiation time of the streamers by recording light emitted. The capacitive divider 2 allows recording the shape and the value of the applied voltage. All voltage characteristics of the PD are determined from the applied voltage measurement. The TI provide directly the leakage current through $R_{0}$. The leakage current can be calculated from the voltage dropped across $R_{0}$. Both methods were used to determine the leakage current for accuracy backup purposes. The increase in the applied $\mathrm{AC}$ voltage $\left(U_{a p p}\right)$ up to the breakdown with the corresponding PMT signal and leakage current is presented in Fig. 4. for illustration purposes to the readers.

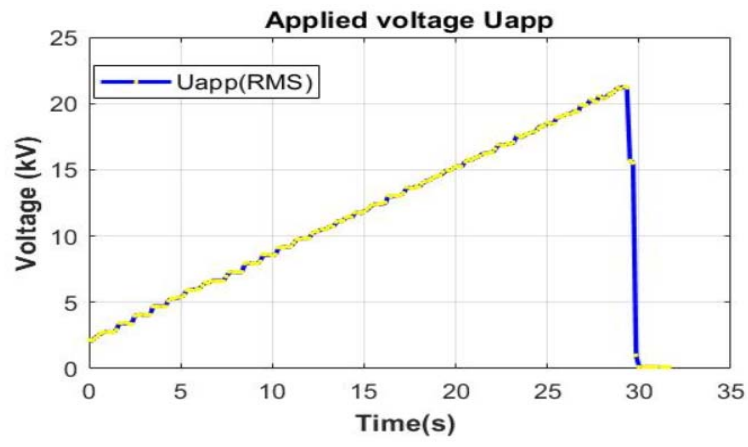

$a$

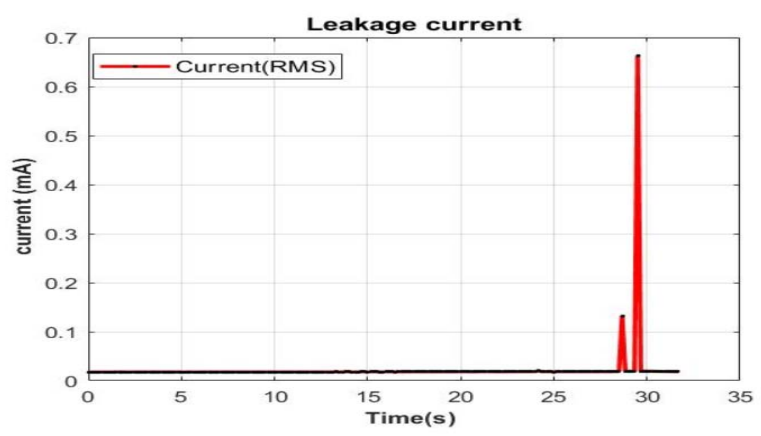

$b$

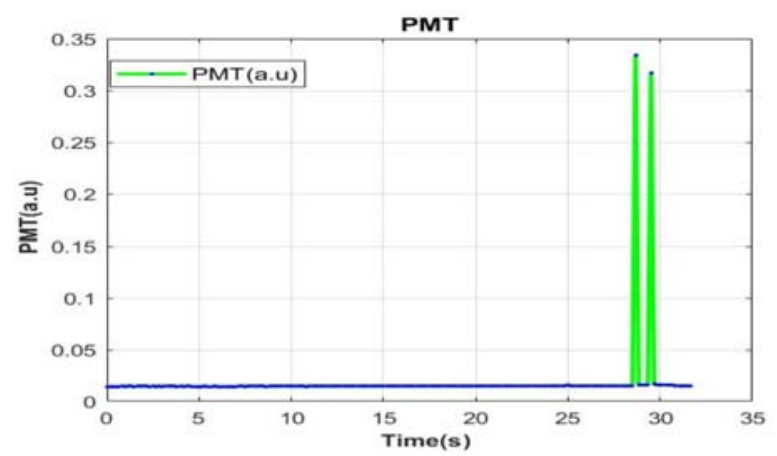

C

Fig. 4. Different signals recorded at $0^{\circ} \mathrm{C}$ for $\mathrm{NE} 1$

\section{Results and Discussion}

The following table (Table 2) summarizes the abbreviations commonly used in this section.

Table 2 Abbreviations table

\begin{tabular}{ll}
\hline Abbreviation & \multicolumn{1}{c}{ Meaning } \\
\hline NE1 & Canola oil \\
\hline NE2 & Soybean oil \\
\hline PD & Partial Discharge \\
\hline PDPIV & Partial Discharge Pre-Inception Voltage \\
\hline PDIV & Partial Discharge Inception Voltage \\
\hline BSIV & Streamers leading to Breakdown \\
& Inception Voltage \\
\hline BDV & Breakdown Voltage \\
\hline PDPIT & Partial Discharge Pre-Inception Time \\
\hline BSIT & Streamer leading to Breakdown Time \\
\hline BDT & Breakdown Time \\
\hline$\Delta t$ & Delay time \\
\hline
\end{tabular}

\subsection{Delay Time $(\Delta t)$}

The analysis of the measurement results allowed determining four parameters: PDPIT, PDIT, BSIT and BDT. Associated to these parameters, four characteristic voltages of the PDs were determined: PDPIV, PDIV, BSIV and BDV. The delay time $\left(\Delta t=t_{B S I T}-t_{P D P I T}\right.$ is the delay time) is defined as the duration measured between the PD PreInception Time (PDPIT) and the streamers leading to breakdown time (BSIT). The illustration and measurement of the delay time are sketched in Fig. 5.

$\mathrm{PD}$ propagation phenomena in insulating fluids play a critical role in sense that it may lead to breakdown. The time between the first PD activities and the inception of streamers leading to breakdown can be a useful parameter providing an idea on the oil's ability to resist breakdown phenomena in the vulnerable condition. Under AC stress, the measurement of the delay time at different temperatures may be an interesting parameter for the performance evaluation of oils. The delay time depends on the dielectric integrity of the oil, moisture content, presence of gas bubbles, concentration of conducting particles, rate of rise of applied voltage, etc. In the present case, moisture content is within the acceptable levels (dried oils) and conducting particles are almost inexistent as the oils are fresh filtered and degassed. 


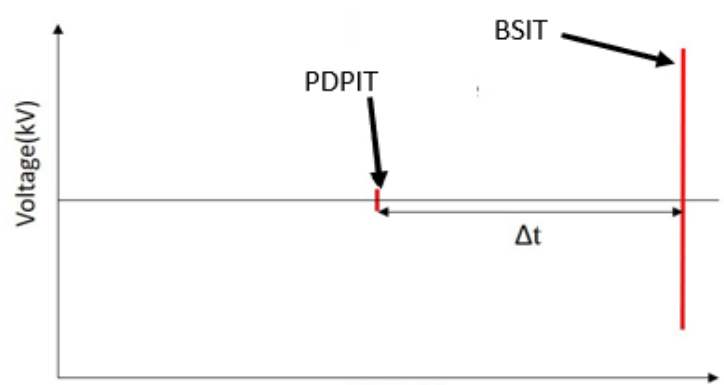

Time(s)

$a$

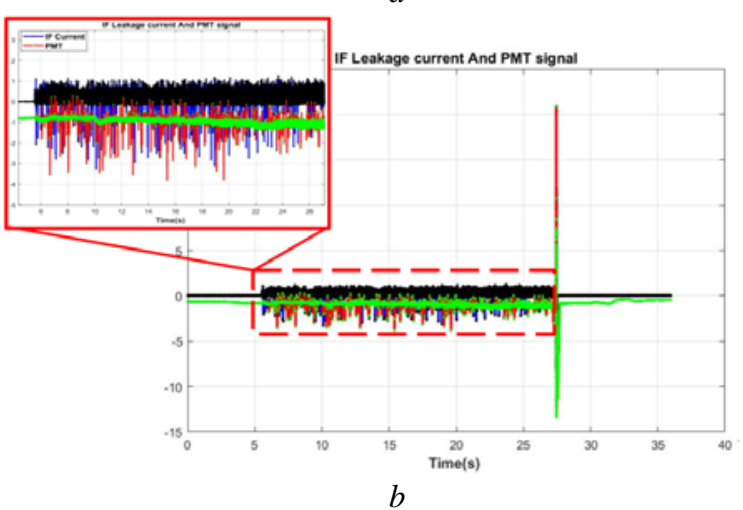

Fig. 5. Illustration of the delay time measurement (a) Sketch, (b) Deriving the delay time from measurement

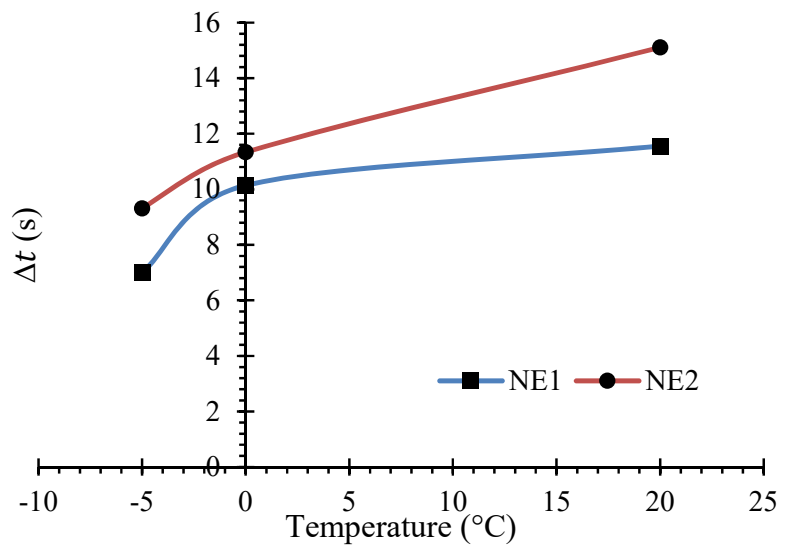

Fig. 6. Delay time measurement for NE1 and NE2 at different temperatures.

Fig. 5, presents the light activity recorded by PMT and leakage current recorded by TI. At first, some leakage currents are observed which are not in phase with the pulses of the PMT signal. The first time of initiation of this leakage current allows determining the pre-initiation voltage of the PDs.

Fig. 6 presents the delay time as a function of temperature for NE1 and NE2. The delay time (time between the time of PDPIT and BSIT) reflects the vulnerability time of the liquid dielectric. In this study $\Delta t$ seems to increase with the increase in the temperature. This result cannot be generalized even for the same liquid dielectric tested under the same conditions because $\Delta t$ is as random as the prebreakdown and breakdown phenomena.
All factors that influence the BDV affect the delay time under AC stress. The rate of rise of the applied voltage can influence the delay time. For example, the rapid rate of increase in the applied voltage involves a rapid increase in the electric field and certainly a reduction in the delay time. The inter-electrode distance and electrode shape may affect the delay time. The assessment of dielectric quality based on the knowledge of $\Delta t$ requires an in-depth study. Also $\Delta t$ requires further investigations in order to establish a correlation with one or more physicochemical parameters.

\subsection{Pre-Inception Voltage}

According to [18], and streamer theory proposed by Dumitrescu [19], a pre-inception current exists for voltages

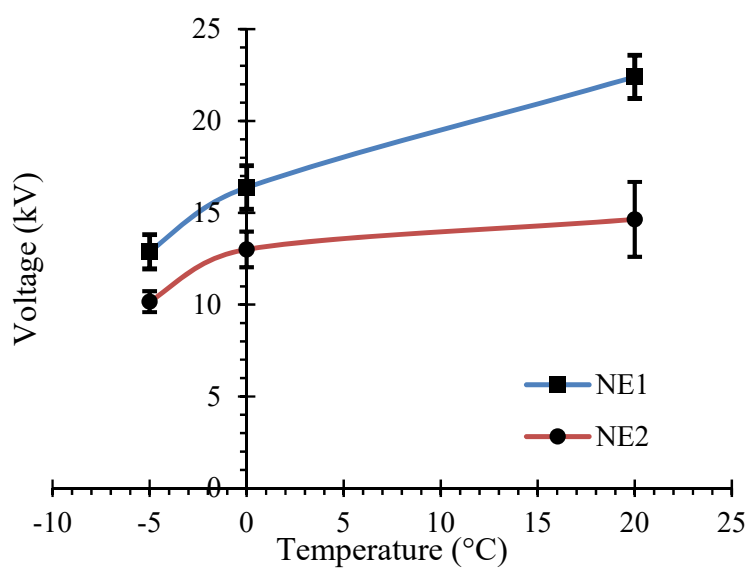

$a$

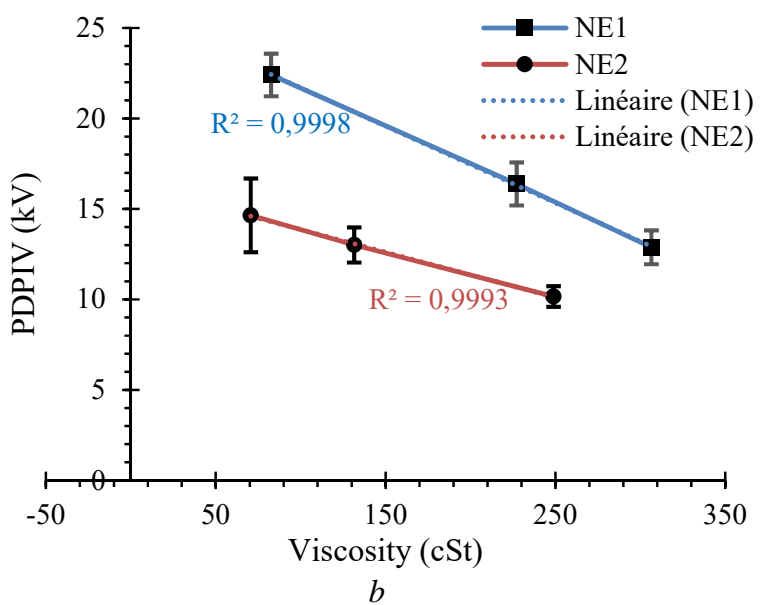

Fig. 7. (a) PDPIV as a function of temperature and (b) PDPIV as a function of viscosity for NE1 and NE2

below the inception voltages. It is also reported that, preinception current is not witnessed by light emission signals. Therefore, at certain voltages, below the inception voltage, there is a probable existence of voltage called pre-inception voltage.

The pre-inception voltage for all the measurements were plotted as a function of temperature and are presented in Fig. 7. The pre-inception voltage increases with increasing temperature. The PDPIV of NE1 is higher than that of NE2 regardless the temperatures. The moisture content in both oils was of the same at $20^{\circ} \mathrm{C}$ (about $50 \mathrm{ppm}$ as delivered). 
However, the pre-initiation voltage of the streamers in NE1 is higher than that of NE2. The bars represent the standard deviation.

\subsection{Streamer Inception Voltage}

In liquids, a breakdown arc is the consequence of the initiation and propagation of ionized gaseous channels, taking place few $\mu$ s before the arc phase [20]. The magnitude of the applied voltage at which the first noticeable streamer evolves is referred as PDIV. The PDIV is an important parameter to understand the dielectric performance of the insulating medium. The PDs in dielectrics are influenced by several factors. Among the factors that influence the characteristics of PDs there are: molecular structure of dielectric liquids, inter-electrode gap, characteristics of the electrode to which the voltage is applied (radius of curvature in the case of a tip electrode), the shape of the applied voltage and the polarity of the voltage, moisture content, acidity, hydrostatic pressure, temperature, experimental conditions, etc [16].

The PDIV is used to design the dielectric arrangements of HV electrical apparatuses. This characteristic has been the subject of several studies [5, 21]. It is well known that streamers develop in the gas phase [16, 19] and the electronic avalanche develops in the liquid phase [19]. The liquid/gas phase transition can be induced by very high local fields at the channels' tips (several MV/cm), able to induce an intense and localized energy dissipation via charge injection and/or multiplication [19, 22].Once streamers are initiated, they propagate to the opposite electrode. The streamer stops when the electric field becomes too small, producing a string of micro-bubbles that dissolve in the liquid [23]. Several studies explain the formation of bubbles in liquid dielectrics, as well as their deformations [18, 24].

A large increase in the viscosity has been observed for some vegetable oils after aging [25]. The viscosity of the oil affects the cooling efficiency of the transformer. Oil temperature rise in turn affects the oxidation and the acidity of the oil. An increase in acidity often results in a decrease in dielectric strength and an increase in moisture content [26]. Dielectric oils used in power transformers are hygroscopic

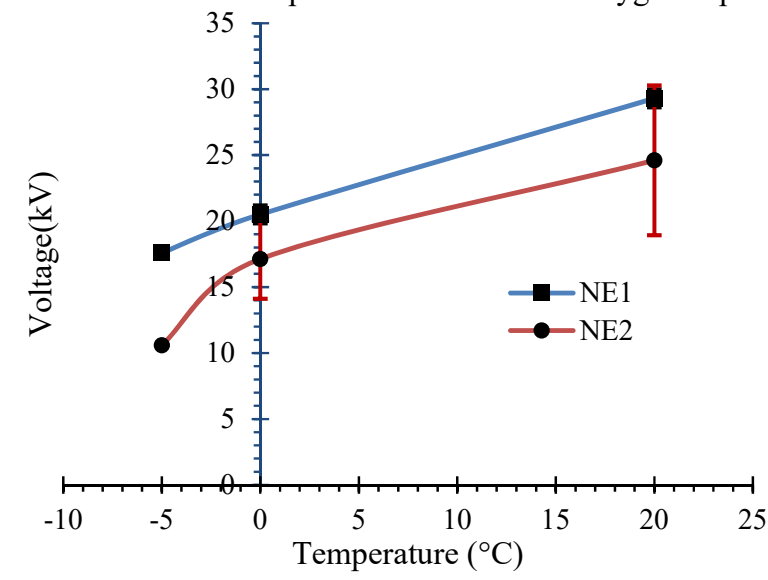

$a$

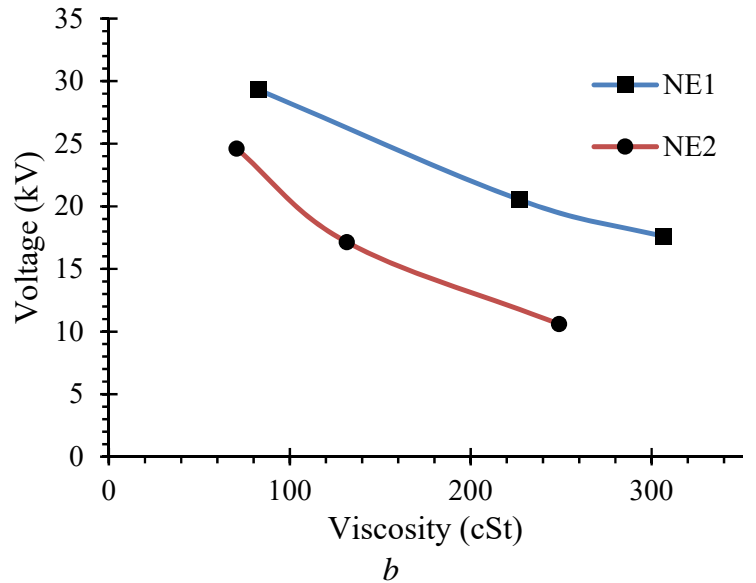

Fig. 8. PDIV and its relation with viscosity for NE1 and NE2 (a) Variation of PDIV, (b) Correlation of PDIV and oil viscosity.

and tend to absorb moisture from the atmosphere [24]. However, ester oils below freezing temperatures $\left(0^{\circ} \mathrm{C}\right)$ tend to release free moisture when compared to hot ester oils. This also influences the acidity level and consequently, the characteristic voltages of the PDs seem to increase with increasing temperature from $-5^{\circ} \mathrm{C}$ to $+20^{\circ} \mathrm{C}$.

In the present study, the level of the applied voltage at which the first PD was observed for NE1 and NE2 at different temperatures is shown in Fig. 8(a). The results show a significant influence of temperature on the PDIV. As in the studied temperature ranges the viscosity increases when the temperature decreases. Fig. 8 (b) depicts the PDIV decrease with increasing viscosity.

\subsection{Breakdown Voltage}

Breakdown is a dynamic process which occurs when the PD reaches the opposite electrode. Due to the high speed of the process and the voltage application procedure, the BSIV and BDV are almost identical as shown in Fig. 9(a) and Fig. 9(b). As mentioned in section 4.3, the BSIV and BDV voltages seem to increase with increasing temperature in the studied range. This may be attributed to the increasing free moisture content in ester oils at low temperatures, which in turn, influences the acidity level. The consequence of high acidity in the liquid dielectric is a reduction in the characteristic voltages of the PDs.

At low temperatures, the hydrostatic pressure of the dielectric increases. By varying the hydrostatic pressure, L. Dumitrescu et al. have shown that the electronic process takes place in a liquid phase and that the streamers take place in a gaseous phase [19]. At low temperature, NE1 and NE2 have high turbidity values. At low temperatures, the turbidity value of NE1 and NE2 increases. This means that the number of suspended particles in the oil increases. It is known that regions of low density such as suspended particles in the oil are easily ionized by the action of the electric field. The rate of ionization increases, and the charge particles propagate, leading to dielectric breakdown.

PDIV and BDV increase with the $\Delta t$ for both oils. However, due to the random nature of the $\Delta t$ this correlation cannot be confirmed. Figure 10 presents the PDIV and BDV as function of $\Delta \mathrm{t}$. 


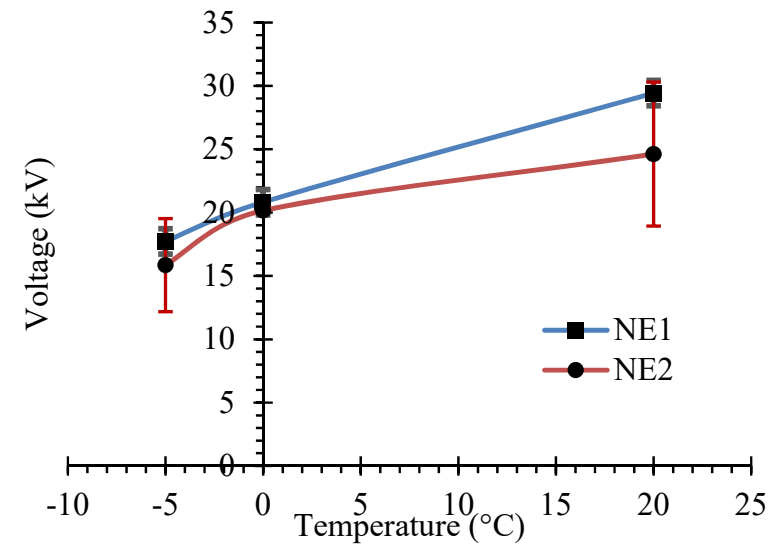

$a$

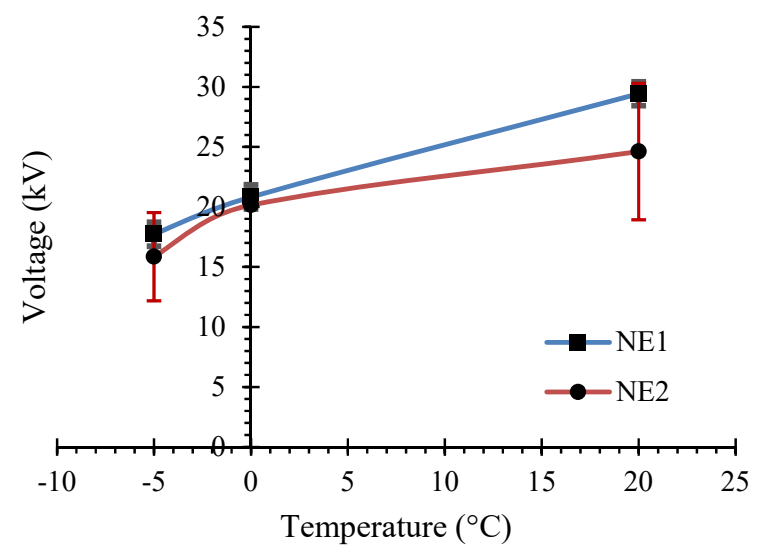

$b$

Fig. 9. (a) BSIV and (b) BDV as function of temperature.

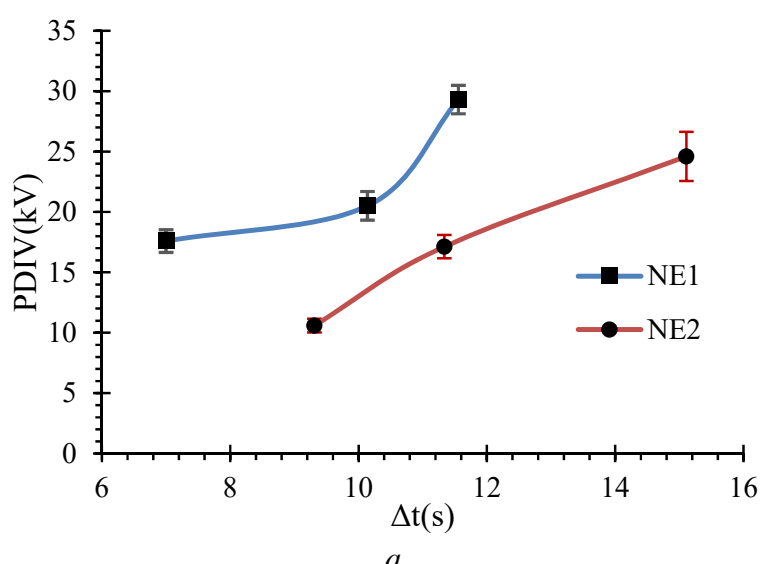

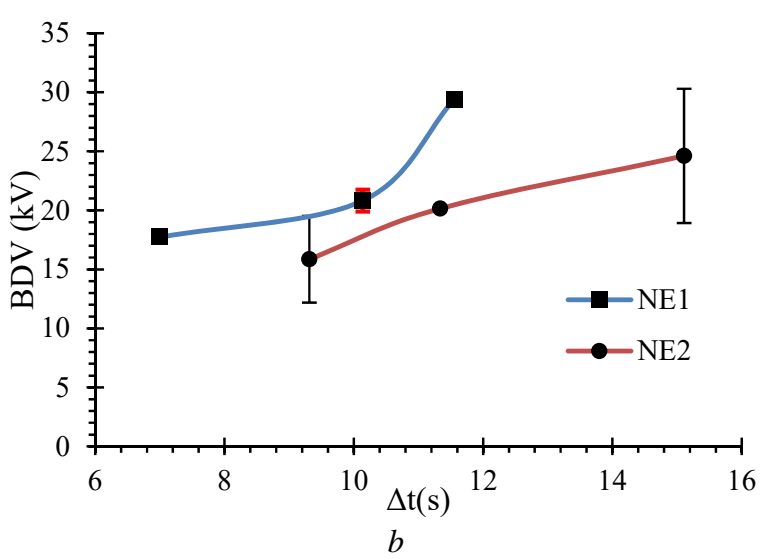

Fig. 10 (a) PDIV and (b) BDV as function of $\Delta t$.

\subsection{PD propagation velocity and Electric Field Stress}

The propagation velocity is an important parameter in the study of PD. It is the ratio between the stopping length and the propagation time $t_{p}$. In [27], it was shown that the stopping length is a function of the applied voltage. It is also reported that, the propagation velocity influences the breakdown voltage of the dielectric fluids. The decreasing of the breakdown voltage can be attributed to the increase of the propagation velocity of the streamers.

The path of streamers through the inter-electrode is not straight and their velocity is therefore not constant. However, when breakdown occurs, the stopping length is assumed to be equal to D (gap). Using the current and PMT signals (Fig. 5), the BSIT and BDT can be determined. The propagation time $t_{p}$ can be computed as shown in (1)

$$
t_{p}=t_{B D T}-t_{B S I T}
$$

Now, using the inter-electrode distance $D=10 \mathrm{~mm}$, the propagation velocity $v_{p}$ is computed according to (2) [27]:

$$
v_{p}=\frac{D}{t_{p}}
$$

Fig. 11 shows the PD propagation velocity as a function of temperature for both fluids. The average propagation velocity of NE2 is constant and about $0.25 \mathrm{~km} / \mathrm{s}$. The viscosity between 70 and $250 \mathrm{cSt}$ for NE2 does not seem to have any effect on its average propagation velocity. In the case of NE1, the propagation velocity decreases with increasing temperature. This may explain the improvement of the BDV when the temperature increases from $-5^{\circ}$ to $+20^{\circ} \mathrm{C}$. However, one cannot conclude that the increase in viscosity leads to an increase in the average propagation velocity of NE1. The viscosity in this study, for NE1 is $82.6087 \mathrm{cSt}$ for $20^{\circ} \mathrm{C}$ and $306.5217 \mathrm{cSt}$ for $-5^{\circ} \mathrm{C}$. This range of viscosity is lower than that considered in [13] where viscosity influences the velocity of the positive streamers of silicone oil. It is seen that, with a reduction in temperature, the BDV decreases because moisture saturation limit of the oils reduces with a reduction in temperature [28]. Hence, this will affect the relative moisture content in the oil. It seems that, according to the applied voltage procedure, PD initiate and propagate in the first and second mode. This is verified by calculating the BDV electric field stress $\left(E_{i}\right)$ at the tip of the needle electrode by using (3) [29]. 


$$
E_{i}=\frac{2 * U_{a p p}}{r_{p} * \ln \left(4 * D / r_{p}\right)}
$$

$U_{a p p}$ : applied voltage $r_{p}$ : radius of curvature of the $\mathrm{HV}$ needle electrode D : electrode gap.

The PDs are generally classified according to their polarity (positive or negative) and propagation speed (slow or fast). The classification of PDs by propagation mode was introduced by Hebner in 1988 and modified by Lesaint in 1996 [17].

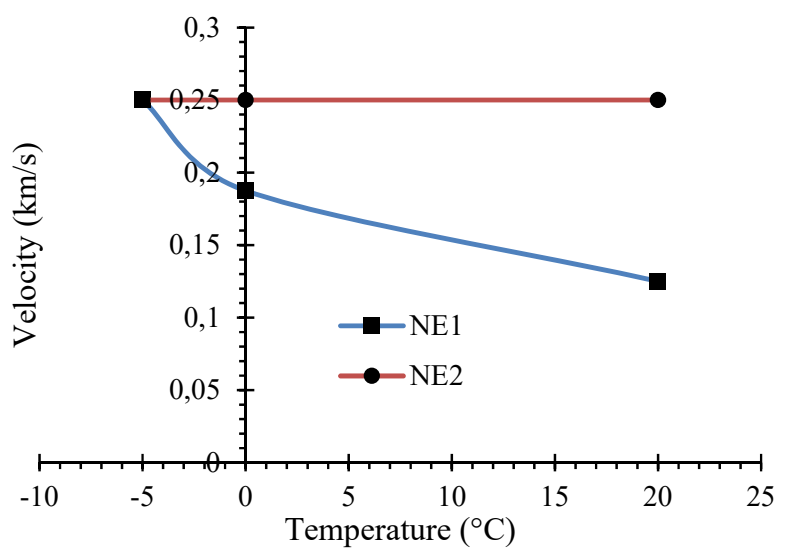

$a$

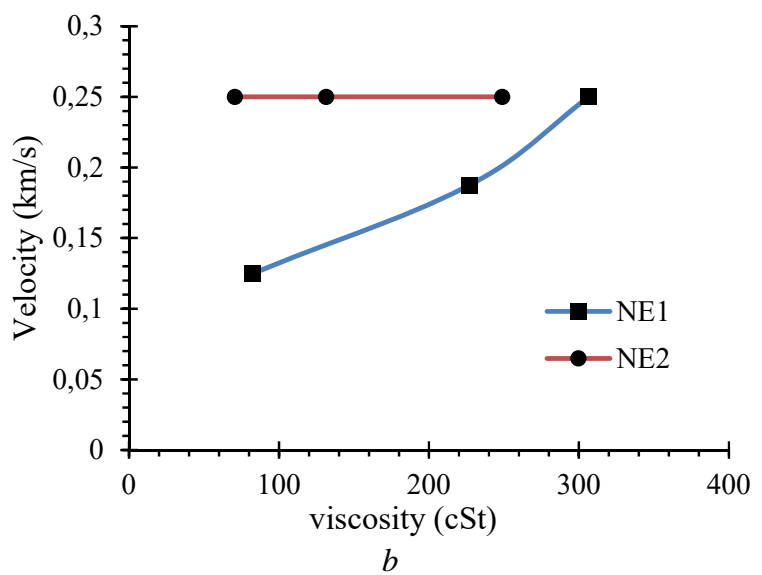

Fig. 11 Propagation velocity (a) as function of temperature (b) as function of viscosity.

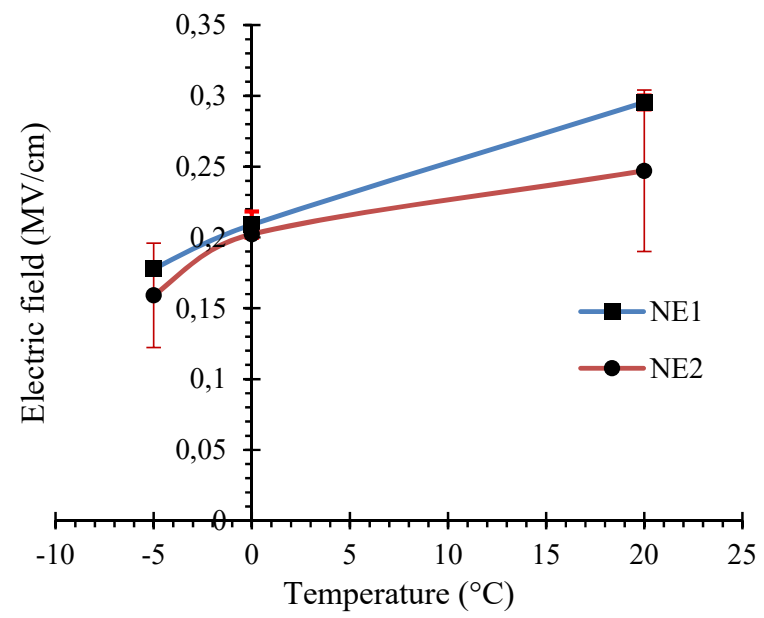

Fig. 12 Electric field as function of temperature.
It is well-established that, local electrical filed stress less than $10 \mathrm{MV} / \mathrm{cm}$ induces development of $1^{\text {st }}$ mode and $2^{\text {nd }}$ mode streamers (slow mode) while local electrical filed stress more than $10 \mathrm{MV} / \mathrm{cm}$ causes development of $3^{\text {rd }}$ mode and 4th mode streamers (fast mode) [30]. Therefore, to understand the streamer modes, electric field stress is calculated at all the measurements and the variations are presented in Fig.12. It is to be noted that, the electric field is between $0.15 \mathrm{MV} / \mathrm{cm}$ to $0.4 \mathrm{MV} / \mathrm{cm}$ for both oils at different temperatures. These values are less than $10 \mathrm{MV} / \mathrm{cm}$ hence the streamers are propagating in slow mode in the both oils. In the frame this work the streamer accelerating voltage is not reached.

\section{Conclusion}

In this paper the influence of temperature on the characteristic voltages of the PDs has been investigated in both natural ester dielectric fluids (NE1 and NE2). The effect of oil viscosity on the streamer inception voltage at different temperatures is also studied. Viscosity is a function of the temperature in the considered temperature range. The $\Delta t$ characteristic that have been introduced in this work seems to have a good correlation with the different characteristic voltages of the PDs. Although a decision taken in the $\Delta t$ period (period of vulnerability) could avoid failure, the $\Delta t$ should be studied in more detail. The characteristic voltages of the PDs seem to decrease when the temperature decreases from $+20^{\circ} \mathrm{C}$ to $-5^{\circ} \mathrm{C}$. The calculation of the electric field at the tip of the needle electrode at BSIV indicates that the PDs studied in NE1 and NE2 propagated in the slow mode. This is confirmed by the calculation of the average velocity. For a transformer, high viscosity has a negative effect on the efficiency of the cooling system.

The results of this study allow understanding the potential feasibility of vegetable oils for use in transformers serving in cold climatic regions. This raise emphasize on cares to consider when switching on the transformer after an extended shutdown in cold countries like Canada in winter. Further, pre-breakdown and breakdown behaviour of specific alternative dielectric fluids with lower pourpoint need to be investigated.

\section{References}

[1] Mohan Rao, U., Fofana, I., Jaya, T., et al.: 'Alternative dielectric fluids for transformer insulation system: research progress, challenges, and future prospects', IEEE Access, 2019,7 , pp. $1-20$

[2] Fernández, I., Ortiz, A., Delgado, F., et al.: 'Comparative evaluation of alternative fluids for power transformers', Electr. Power Syst. Res., 2013, 98, pp. 58-69

[3] Mohan Rao, U., Fofana, I., Rozga, P., et al.: 'A Review on pre-breakdown phenomena in ester fluids," IEEE DEIS Study Gr. Artic. IEEE Trans. Dielectr. Electr. Insul., 2020, (In press)

[4] Chen, X., Li. J., Lv, Y.: 'Electrical aging characteristics of natural ester oil-paper insulation respectively considering temperature and moisture', Proc. IEEE Int. Conf. on High Voltage Engg. and Appl., Chengdu, 2016, pp. 1-4 
[5] Rozga, P.: 'Using the light emission measurement in assessment of electrical discharge development in different liquid dielectrics under lightning impulse voltage', 2016 Electr. Power Syst. Res., 140, pp. 321-328

[6] Ghani, S., Muhamad, N. A., Noorden, N., et al.: 'Methods for improving the workability of natural ester insulating oils in power transformer applications: A review', Electr. Power Syst. Res., 2018, 163, pp. 655-667

[7] Unge, M., Singha, S., Dung, V., et al.: 'Enhancements in the lightning impulse breakdown characteristics of natural ester dielectric liquids', Appl. Phys. Lett., 2013, 102, (17), pp. $1-5$

[8] Muslim, J., Lesaint, O., Hanna. R., et al.: 'Streamer generation and propagation in dibenzyltoluene and ester liquids under high temperature', Proc. IEEE Int. Conf. on Dielec. Liq., Roma, Italy, 2019, pp. 1-4

[9] Bourkas, P. D., Karagiannopoulos, C. G., Agoris. D. P., et al.: 'Temperature effects on partial discharges in the combined system of a solid-liquid dielectric during lightning impulse voltage', Proc. IEEE Int. Sym. on Electr. Insul., Arlington, USA, 1998, 2, pp. 631-635

[10] Fofana, I.: '50 Years in the Development of insulating liquids', IEEE Electr. Insul. Mag., 2013, 29, (5), pp. 13-25

[11] Saha, T. K., Purkait, P.: 'Investigations of temperature effects on the dielectric response measurements of transformer oil-paper insulation system', IEEE Trans. Power Deliv., 2008, 23, (1), pp. 252-260

[12] Stanek, M., Rozga, P., Rapp, K.: 'Comparison of lightning characteristics of selected insulating synthetic esters with mineral oil', Proc. Int. Conf. on Dielectr. Liq., Manchester, UK, 2017, pp. 1-4

[13] Yamada, H., Sato, T.: 'High-speed electro-optical measurement of pre-breakdown current in dielectric liquids', IEEE Trans. Electr. Insul., 1985, EI-20, (2), pp. 261-267.

[14] Aka-Ngnui, Beroual, A., Perrier, C.: 'Pre-breakdown phenomena in synthetic ester and silicone oils for power transformers', Proc. Int. Conf. on Dielectr. Liq., FC, France, 2008, pp. 1-4.

[15] Top, T. V., Massala, G., Lesaint, O.: 'Streamer propagation in mineral oil in semi-uniform geometry', IEEE Trans. Dielectr. Electr. Insul., 2002, 9, (1), pp. 76-82.

[16] Dung, N. V., Hoidalen, H. K., Linhjell, D., et al.: 'Effects of reduced pressure and additives on streamers in white oil in long point-plane gap', J. Phys. D. Appl. Phys., 2013, 25, pp $1-16$.

[17] Mohan Rao, U., Fofana, I., Jaya, T., et al.: 'Preliminary study of ester-based fluid for application in transformers serving in cold climatic regions', Proc. CIGRE Canada Ann. Sess., Montreal, Canada Sept. 2019, pp. 1-6.
[18] Hestad, O. L., Ingebrigsten, S., Lundgaard, L. E.: 'Streamer initiation in cyclohexane, Midel 7131 and Nytro 10X', Proc. IEEE Int. Conf. on Dielectr. Liq., Coimbra, Portugal, 2005, pp. 123-126

[19] Dumitrescu, L., Lesaint, O., Bonifaci, N, et al.: 'Study of streamer inception in cyclohexane with a sensitive charge measurement technique under impulse voltage', J. Electrostat., 2011, 53, (2), pp. 135-146.

[20] Lesaint, O.: 'Streamers in liquids: Relation with practical high voltage insulation and testing of liquids', Proc. IEEE Int. Conf. on Dielectr. Liq., FC, France, 2008, pp. 1-6.

[21] Kattan, R., Denat, A., Lesaint, O.: 'Generation, growth, and collapse of vapor bubbles in hydrocarbon liquids under a high divergent electric field', J. Appl. Phys., 1989, 66, (9) pp. 4062-4066

[22] Beroual, A., Zahn, M., Badent, A., et al.: 'Propagation and structure of streamers in liquid dielectrics,' IEEE Electr. Insul. Mag., 1988, 14, (2), pp. 6-17

[23] Lewis, T. J.: 'A new model for the primary process of electrical breakdown in liquids', IEEE Trans. Dielectr. Electr. Insul., 1988, 5, (3), pp. 306-315.

[24] Wahab, M. A. A., Hamada, M. M., Zeitoun, A. G., et al.: 'Novel modeling for the prediction of aged transformer oil characteristics,' Electr. Pow. Syst. Res., 1999, 51, (1), pp. 6170.

[25] Fofana, I., Bouaïcha, A., Hadjadj, et al.: 'Early stage detection of insulating oil decaying', Proc. IEEE Int. Conf. on Electr. Insul. and Dielectr. Pheno., West Lafayette, IN, 2010, pp. 1-4.

[26] Chandrasekar, S., Montanari, G. C.: 'Analysis of partial discharge characteristics of natural esters as dielectric fluid for electric power apparatus applications', IEEE Trans. Dielectr. Electr. Insul., 2014, 21, (3), pp. 1251-1259

[27] V. H. Dang, A. Beroual, E. Al-Ammar, and M. Qureshi, "Streamer propagation in seed based insulating oils under lightning impulse voltages," ICHVE 2012 - 2012 Int. Conf. High Volt. Eng. Appl., pp. 659-662, location? and date June ?2012.

[28] Przybyłek, P., Gielniak, J.: 'Concentration analysis of gases formed in mineral oil, natural ester, and synthetic ester by discharges of high energy', Eksploatacja i Niezawodność, 2018, 20, (3), pp. 435-442.

[29] Lu. W., Liu, Q.: 'Effect of cellulose particles on impulse breakdown in ester transformer liquids in uniform electric fields', IEEE Trans. Dielectr. Electr. Insul., 2015, 22, (5), pp. 2554-2564.

[30] Rozga, P.: 'Streamer propagation in a non-uniform electric field under lightning impulse in short gaps insulated with natural ester and mineral oil', Bulle. Polish Acad. Sci. Tech. Sci., 2016, 64, (1), pp. 171-179. 